\title{
Analisys of the Quality of Customer Service Satisfactory of Baitul Maal Wattamwil (BMT) Tamzis at Daerah Istimewa Yogyakarta and Jawa Tengah
}

\author{
Agus Siswanto \\ Universitas Ahmad Dahlan
}

Abdul Choliq Hidayat*

Universitas Ahmad Dahlan

hacholiqh@gmail.com

\begin{abstract}
The research aim was to analyse the quality of customer service satisfactory of BMT Tamzis at Daerah Istimewa Yogyakarta and Jawa Tengah, as the syariah finance, who has 33 (thirty three) branchs, and its headquarter at Wonosobo, Jawa Tengah. It has at least 2.000 customers in 2018. BMT Tamzis needs some feedback in order to increase their quality of customer service satisfactory as high as possible to reach optimum level, and fulfill qualification of succeed finance business. This research wanted to measure the up dated customer service satisfactory and gave feedback to BMT Tamzis. The research method used quantitative approach to primary data of customer questioneer and scondary data of BMT Tamzis's headquarter. The questioneers had distributed to customers by proporsional random sampling about 330 examplars, returned back about 320 examplars, and than have been calculated by SPSS method version 10.0. The result research was customer satisfactory perception toward BMT Tamzis reached good and significance level at all branchs, at point 4.031 root mean at 1 until 5 Likert scale. They favored assurance dimension at point 4.215, and than tangibles (3.990), responsiveness (3.989), reliability (3.976), and emphaty (3.986). To be adviced that all branch leaders must increase giving their services until reach the highest level of all dimensions, that are : tangibles, responsiveness, reliability, emphaty, dan assurance.
\end{abstract}

Key word: satisfactory, service, customer.

\section{Landasan Teori dan Pengembangan Hipotesis}

Baitul Maal Wat Tamwil (BMT) sebagai lembaga keuangan mikro berbasis syariah mempunyai peran pokok yang penting dalam masyarakat, yakni sebagai lembaga perantara keuangan, maka hal dasar yang sangat dibutuhkan adalah dapat menjalankan peran penting tersebut dengan mendapatkan kepercayaan dan keyakinan dari masyarakat. Masyarakat mempercayai sepenuhnya akan fungsi dan perannya sebagai lembaga keuangan yang membantunya, dan mampu melayani masyarakat sebagai nasabah dan menjadi mitra yang saling membutuhkan. Kemitraan itu berupa kepercayaan masyarakat dalam bentuk menyimpan dana serta sebagai lembaga keuangan dapat memberikaan suatu perlindungan dan jaminan atas dana tersebut. Disamping itu, diharapkan masyarakat dapat percaya bahwa sebagai lembaga keuangan, BMT akan mampu memenuhi kebutuhan masyarakat dalam hal keuangan baik itu masalah pendanaan maupun pembiayaan serta pembinaan. Itulah sebabnya saat ini berbagai BMT berlomba-lomba untuk dapat memberikan pelayanan yang terbaik dan memuaskan bagi setiap nasabah sehingga masing-masing 
berharap mampu bertahan sebagai entitas bisnis yang berkelanjutan dengan pelayanan prima.

Faktor pelayanan menjadi begitu sangat penting di tengah persaingan yang semakin ketat, dan kata kuncinya adalah kepuasan nasabah agar tetap dapat mempertahanankan nasabah lama dan berusaha mendapatkan nasabah yang baru.

Menurut Webster dalam Andespa (2016:143-159) konsep kepuasan customer merupakan hasil dari kesuksesan sebagai penyedia produk memenuhi harapan konsumen dan secara defenitif mempengaruhi perubahan sikap, melakukan pembelian ulang dan terbentuknya loyalitas. Kualitas layanan adalah salah satu atribut penting dalam industri jasa, termasuk BMT, di samping masalah keamanan dan kepastian, serta harga (yang sesuai dengan kualitas). Kualitas Pelayanan lembaga keuangan ditentukan oleh penilaian dari nasabahnya, merupakan sesuatu yang sangat penting, karena akan memiliki karakteristik hight-contact sevice dan tingkat kompetisi yang sangat tinggi. Nasabah yang puas akan mendorong terciptanya suatu publisitas public kepada calon-calon nasabah potensial baru, dan pada perjalanannya akan menghasilkan nasabah-nasabah yang setia.

Menurut Tjiptono (2012:11) ada lima faktor yang relevan untuk menjelaskan kualitas pelayanan yang di kenal dengan model SERVQUAL yaitu reliability, responsiveness, assurance, empathy, dan tangibles. Kelima factor kualitas pelayanan tersebut merupakan kunci utama untuk meningkatkan kepuasan nasabah yang pada akhirnya berujung pada loyalitas nasabah.

Pelayanan yang berkualitas dan mampu memuaskan pelanggan merupakan kunci loyalitas pelanggan karena terbanyak konsumen yang tidak puas memilih untuk tidak melakukan pengaduan dan sebagian besar cukup menghentikan pembeliannya (Kotler, 1997).

Berdasarkan latar-belakang masalah diatas, maka masalah dalam penelitian ini dapat dirumuskan sebagai berikut;

a. Apakah faktor-faktor pelayanan yang terdiri reliability, responsiveness, assurance, emphaty dan tangible secara parsial mempengaruhi kepuasan nasabah BMT Tamzis?

b. Apakah faktor-faktor reliability, responsiveness, assurance, emphaty dan tangible secara bersama-sama mempengaruhi kepuasan nasabah BMT Tamzis ?

Tujuan dari penelitian ini adalah sebagai berikut;

a. Menguji apakah faktor-faktor pelayanan yang terdiri dari reliability, responsiveness, assurance, emphaty dan tangible secara parsial mempengaruhi kepuasan nasabah BMT Tamzis di DIY dan Jateng.

b. Menguji apakah faktor-faktor reliability, responsiveness, assurance, emphaty dan tangible secara bersama-sama mempengaruhi kepuasan nasabah BMT Tamzis di DIY dan Jateng.

Parasuraman et al. (1985, 1988), menjelaskan tentang perkembangan dari scala multiple item untuk mengukur harapan dan persepsi pelanggan, serta gap diantara keduanya dalam dimensi-dimensi utama kualitas jasa. Terdapat beberapa kriteria yang digunakan oleh nasabah dalam menilai mutu pelayanan. Kriteria tersebut meliputi 10 dimensi potensial yang saling melengkapi yaitu tangibles, reliability, responsiveness, communication, credibility, security, competence, courtesy, understanding dan access. Dimensi dapat disederhanakan menjadi 5 dimensi yaitu tangibles, reliability, responsiveness, assurance dan empathy. Cronin and Taylor (1992), mengembangkan metode pengukuran kualitas pelayanan serta untuk mengetahui hubungan antara kualitas pelayanan, kepuasan konsumen dan intensitas pembelian. Kualitas pelayanan merupakan dasar dari kepuasan konsumen dan kepuasan konsumen mempunyai pengaruh yang lebih 
besar terhadap intensitas pembelian dari pada kualitas pelayanan. Taylor and Baker (1994), menunjukan bahwa kepuasan pelanggan pada tiga industri (jasa taman parkir, jasa transportasi penerbangan, jasa telekomunikasi jarak jauh) berpengaruh terhadap intensitas pembelian. Martilla dan James (1977), menunjukkan ukuran tingkat kepuasan atau kualitas pelayanan suatu industri jasa berdasarkan persepsi pelanggan, menghasilkan model yaitu Importance Performance Analysis atau analisis tingkat kepentingan dan kinerja/kualitas pelayanan. Selain itu juga menghasilkan Diagram Kartesius untuk melihat letak dari unsurunsur pelaksanaan faktor-faktor atau atribut yang mempengaruhi kepuasan pelnaggan perusahaan (dalam Supranto, 2002).

Ada empat karakteristik pokok jasa yang membedakannya dengan barang (Tjiptono, 1997). Keempat karakteristik tersebut meliputi:

a. Intangibility

Jasa bersifat intangible, artinya tidak dapat dilihat, dirasa, diraba, dicium atau didengar sebelum dibeli.

b. Perishability

Jasa yang merupakan komoditas tidak tahan lama dan tidak dapat disimpan. Menurut Stanton et al. (1991), ada pengecualian dalam karakteristik perishability dan penyimpanan jasa. Dalam kasus tertentu jasa dapat disimpan yaitu dalam bentuk pemesanan, peningkatan permintaan akan suatu jasa pada saat permintaan sepi dan penundaan penyampaian jasa.

c. Inseparability

Jasa dijual terlebih dahulu baru kemudian diproduksi dan dikonsumsi. Interaksi antara penyedia jasa dan pelanggan bersifat khusus.

d. Variability

Jasa bersifat sangat variabel karena merupakan non standardized output, yang artinya banyak variasi bentuk, kualitas dan jenis tergantung pada siapa, kapan dan dimana jasa tersebut dihasilkan dan dipesan.

Terdapat dua faktor utama yang mempengaruhi kualitas jasa menurut Parasuraman et al. (1985), yaitu;

1. Apabila jasa yang diterima atau dirasakan (perceived service) sesuai dengan yang diharapkan, maka kualitas jasa dipersepsikan baik dan memuaskan.

2. Apabila jasa yang diterima melampaui harapan pelanggan, maka kualitas jasa dipersepsikan sebagai kualitas yang ideal.

Model-model yang dapat digunakan untuk menganalisis kualitas jasa, tergantung pada tujuan analisis, jenis perusahaan, dan situasi pasar. Setidaknya terdapat tiga kelompok utama (Kotler, 1997), yaitu customer-perceived quality, the processes in the creation of the service, dan the whole service (system models).

Teori lima dimensi pokok kualitas jasa (Zeithaml et al., 1996:118), yaitu:

1. Bukti langsung (tangibles); meliputi fasilitas fisik, perlengkapan pegawai, dan sarana komunikasi.

2. Keandalan (reliability); yakni kemampuan memberikan pelayanan yang dijanjikan dengan segera, akurat, dan memuaskan.

3. Daya tanggap (responsiveness); yaitu keinginan para staf untuk membantu para pelanggan dan memberikan pelayanan dengan tanggap.

4. Jaminan (assurance); mencakup pengetahuan, kemampuan, kesopanan dan sifat dapat dipercaya yang dimiliki para staf, bebas dari bahaya risiko dan keragu-raguan.

5. Empati (emphaty); meliputi kemudahan dalam melakukan hubungan, komunikasi yang baik, perhatian pribadi, dan memahami kebutuhan para pelanggan. 
Penelitian Ikhwal (2017), menganalisis Faktor-faktor Yang Mempengaruhi Kepuasan Nasabah Terhadap Pelayanan Bank Syariah Kota Batam. Analisis dari pengolahan data pengaruh bukti fisik, kehandalan, tanggapan, jaminan dan empati terhadap kepuasan nasabah matriks kolerasi didapat dengan nilai Barlett Test of Sphericity (BTS) dengan nilai signifikan sebesar 0,00. Ini menunjukan bahwa matriks berkorelasi terdapat hubungan antara variabel-variabel dalam populasi.

Penelitian Febriana (2016), menganalisis Kualitas Pelayanan Bank Terhadap Kepuasan Nasabah Pada Bank Muamalat Indonesia Kantor Cabang Pembantu Tulungagung.mengkaji pengaruh variabel kualitas pelayanan bank terhadap kepuasan nasabah. Penelitian dilakukan pada Bank Muamalat Indonesia kantor cabang pembantu Tulungagung. Metode dalam menilai kepuasan nasabah menggunakan analisis SERVQUAL atau analisis gap. Pengumpulan data pada penelitian ini menggunakan angket yang diberikan kepada 196 sampel dengan unit analisis menggunakan analisis regresi. Berdasarkan hasil analisis membuktikan bahwa secara simultan dimensi CARTER yang terdiri dari compliance, assurance, reliability, tangibles, empathy, dan responsiveness berpengaruh signifikan terhadap kepuasan nasabah. Analisis servqual menunjukkan bahwa dari keseluruhan instrumen dimensi CARTER terdapat kesenjangan atau gap antara harapan nasabah dengan kualitas pelayanan. Analisis diagram kartesius menunjukkan bahwa ada beberapa hal yang perlu diprioritaskan untuk diperbaiki oleh Bank Muamalat Indonesia KCP Tulungagung, antara lain adalah tentang: sistem tabungan, ketepatan waktu pelayanan seperti yang telah dijanjikan, ketersediaan ATM, Peralatan yang digunakan, hubungan antara pegawai dengan nasabah, perhatian personal bank kepada nasabah, dan respon customer service dalam menanggapi keluhan nasabah.

Penelitian Rokhman (2016). Pengaruh Biaya, Angsuran Dan Kualitas Pelayanan Terhadap Kepuasan Nasabah Pembiayaan BMT Di Kabupaten Kudus. Penelitian Analisis Kepuasan Konsumen Herni Justiana Astuti menggunakan Servqual Model dan Important Performance Analysis Model menyimpulkan bahwa Kepuasan pelanggan merupakan evaluasi spesifik terhadap keseluruhan pelayanan yang diberikan pemberi jasa, sehingga kepuasan pelanggan hanya dapat dinilai berdasarkan pengalaman yang pernah dialami saat proses pemberian pelayanan. Kepuasan pelanggan terutama dibidang jasa menjadi keharusan agar perusahaan tetap sukses. Perbedaan antara harapan konsumen mengenai kinerja dari perusahaan dan penilaian konsumen mengenai kinerja aktual memberikan suatu persepsi konsumen atas kualitas jasa. Perbedaan tersebut terjadi karena adanya gap (kesenjangan) antara harapan pelanggan dan kenyataan (kinerja) pelayanan yang diterima; kesenjangan tersebut ada sebagai akibat tidak terpenuhinya harapan para pelanggan. Agar dapat mengurangi kesenjangan tersebut penyedia jasa perlu mengadopsi cara untuk menghilangkan kesenjangan berdasarkan temuan Parasuraman dan Zethaml (1994).

Berdasarkan latar-belakang masalah, rumusan masalah, tujuan penelitian dan landasan teori, maka hipotesis yang diajukan dalam penelitian ini adalah:

H1: Faktor-faktor pelayanan yang terdiri dari tangible, reliability, responsiveness, assurance, dan emphaty secara parsial mempengaruhi kepuasan nasabah BMT Tamzis di DIY dan Jateng.

$\mathrm{H} 2$ : Faktor-faktor tangible, reliability, responsiveness, assurance, dan emphaty secara bersama-sama mempengaruhi kepuasan nasabah BMT Tamzis di DIY dan Jateng. 


\section{Metode Penelitian}

Variabel yang digunakan dalam penelitian ini adalah sebagai berikut:

1. Kepuasan pelanggan faktor Tangible meliputi;

a. Kepuasan pelanggan ketika berhubungan dengan bagian marketing.

b. Kepuasan pelanggan ketika berhubungan dengan bagian teller atau kasir.

c. Kepuasan pelanggan ketika berhubungan dengan bagian customer service.

d. Kepuasan pelanggan ketika berhubungan dengan bagian keamanan.

e. Kepuasan pelanggan yang berhubungan dengan fasilitas yang ada di BMT Tamzis;

- penampilan karyawan

- keramahan karyawan

- tersedianya brosur dan formulir penjelasan program.

- kenyamanan ruangan

- jalur antrian

- perhatian dan bantuan yang diberikan karyawan

- proses penyelesaian transaksi

- kemudahan menghubungi lewat telepon

- sarana parkir

- fasilitas ATM (Anjungan Tunai Mandiri)

2. Kepuasan Nasabah faktor Reliability meliputi :

a. Kecepatan pelayanan

b. Keakuratan atau ketepatan jumlah

c. Kesesuaian rencana dan realisasi.

3. Kepuasan Nasabah faktor Responsiveness meliputi :

a.Kesiapan karyawan dalam memberikan bantuan dan pelayanan kepada pelanggan.

b.Penjelasan serta pembinaan atas penggunaan pendanaan dan pembiayaan.

c. Penjelasan program yang telah disepakati.

4. Kepuasan Nasabah faktor Assurance meliputi :

a. Pengetahuan dan kemampuan yang dimiliki karyawan

b. Sopan santun karyawan

c. Sifat dapat dipercaya yang dimiliki karyawan

d. Ketepatan perjanjian pertemuan.

5. Kepuasan Nasabah faktor Emphaty meliputi :

a. Sifat mudah bergaul dan berkomukasi dari karyawan.

b. Perhatian pribadi yang diberikan karyawan.

c. Pemberian alternatif solusi jika mendapatkan kesulitan.

d. Penjelasan ulang dan tindak lanjut program jika diperlukan.

Dalam penelitian ini sampel yang digunakan adalah nasabah BMT Tamzis yang aktif minimal 1 (satu) tahun terakhir, yakni tahun 2018. Metode pengambilan sampel yang digunakan adalah purposive random sampling, yaitu suatu cara pengambilan sampel, dimana sampel yang dipilih didasarkan pada proporsi yang diusahakan secara adil sesuai keperluan. Sampel yang diambil didasarkan pada pertimbangan; (1) nasabah BMT Tamzis yang aktif minimal satu tahun terakhir, (2) nasabah yang dijadikan sampel adalah nasabah 
yang merupakan nasabah dari semua produk. Secara random berarti bahwa pengambilan sampel dilakukan secara random atau acak, sehingga setiap anggota populasi mempunyai kesempatan yang sama untuk dipilih menjadi sampel.

Populasi penelitian adalah seluruh nasabah BMT Tamzis di DIY dan Jateng. Karena populasi penelitian ini dikategorikan besar, yakni lebih dari 1.000 orang maka peneliti menggunakan sampel dari nasabah BMT Tamzis dengan menggunakan teknik sampling. Teknik sampling yang digunakan adalah cluster sampling (sampling daerah). Teknik ini digunakan untuk menentukan sampel jika objek yang akan diteliti atau sumber data sangat luas (Azwar, 1998).

Teknik ini dilakukan melalui satu tahap, yaitu tahap menentukan sampel jumlah kantor cabang di kabupaten atau kota dan tahap kedua menentukan jumlah nasabah untuk tiap kantor cabang di kabupaten atau kota yang telah ditentukan. Besarnya sampel masingmasing kantor cabang ditentukan adalah 10 nasabah dari populasi. Jumlah kantor cabang se DIY sebanyak 6 cabang : Kotagede, Ahmad Dahlan, Sido Agung Godean, Plaza A-6 Bantul, Catur Tunggal Depok Sleman, Wates Kulon Progo. dan Jateng sebanyak 27 cabang : Purwokerto (1): Pemuda; Banyumas (1): Wangon; Purbalingga (1) : Kalimanah; Cilacap (1): Kroya; Banjarnegara (4) : Batur, Klampok, Plaza Wanadadi, Banjar Kota; Wonosobo (7) : Kota, Kejajar, Pasar Induk, Sapuran, Kertek, Plaza Kaliwiro, Wadaslintang; Purworejo (1) : Pangenrejo; Temanggung ( 2) : Parakan, Kertosari; Kendal (2) : Weleri, Ruko Kaliwungu Trade Center; Magelang (3) : Ruko Prayudan, Pucungrejo Muntilan. Secang; Klaten (2) : Prambanan, Jatinom; Salatiga (1) : Kotamadya Salatiga; Boyolali (1) : Kiringan; sehingga total 33 cabang. Setiap cabang diberikan sampling masing-masing sebanyak 10 sehingga jumlah sampel seluruhnya adalah 330 nasabah.

Data primer (primary data) yaitu data yang dikumpulkan sendiri oleh perorangan atau organisasi secara langsung melalui obyeknya (Azwar, 1998). Dalam penelitian ini data primer adalah data yang dikumpulkan dari responden yang berupa data mengenai penilaian mereka terhadap pelayanan yang diberikan oleh BMT Tamzis di DIY dan Jateng.

Teknik pengumpulan data yang digunakan untuk memperoleh data primer adalah dengan kuesioner. Kuesioner atau daftar pertanyaan diberikan kepada responden terpilih. Daftar pertanyaan berisi pertanyaan yang ada hubungannya dengan variabel penelitian.

Selain data primer, penelitian ini juga menggunakan data sekunder (secondary data), yaitu data yang diperoleh dalam bentuk publikasi. Data sekunder dalam penelitian ini antara lain data mengenai perkembangan bisnis dan jumlah kantor cabang BMT Tamzis.

Teknik analisis data menggunakan dua model (Arikunto, 2009), yakni :

1. Teknik analisis kualitatif

Teknik analisis kualitatif atau deskriptif digunakan untuk melakukan deskripsi terhadap variabel-variabel penelitian. Hal ini untuk memberikan kejelasan dan batasan terhadap variable penelitian.

2. Teknik analisis kuantitatif

Tujuan teknik analisis kuantitatif untuk melakukan pengujian terhadap hipotesis pada penelitian ini.

Pengujian validitas dan reliabilitas adalah proses pengujian terhadap setiap butir pertanyaan yang ada pada kuesioner. Ada dua syarat penting yang berlaku pada sebuah kuesioner, yaitu syarat valid dan reliabel. Kuesioner dikatakan valid jika pertanyaanpertanyaan yang ada mampu untuk mengungkapkan sesuatu yang akan diukur oleh questioner tersebut. Kuesioner dikatakan reliable jika jawaban dari seseorang terhadap pertanyaan yang ada selalu konsisten atau stabil dari waktu kewaktu. Uji validitas dan reliabilitas dilakukan sebelum kuesioner diedarkan secara resmi (Arikunto, 2009). 
Dalam penelitian ini uji validitas dan reliabilitas dilakukan dengan penyebaran kuesioner kepada 40 orang responden uji coba yang tidak terkait sebagai responden penelitian. Pengujian validitas dan reliabilitas dilakukan dengan menggunakan program komputer SPSS versi 10.0. (Ghozali, 2002).

Pengujian asumsi dilakukan dengan menggunakan uji autokorelasi, uji multikolinieritas, uji heterokedastisitas, dan uji normalitas.

Hipotesis yang telah dirumuskan diuji dengan menggunakan beberapa teknik pengujian, yaitu linier multiple regression, uji t statistik, dan uji F statistik.

Pengujian Linier Multiple Regression (Regresi Linier Berganda) sesuai Arikunto (2009) dilakukan untuk mengetahui apakah faktor tangible, reliability, responsiveness, asurance, dan emphaty mempengaruhi kepuasan pelanggan terhadap pelayanan yang diberikan sehingga dapat dirumuskan persamaan regresinya.

Sedangkan Rumus persamaan regresi-nya adalah sebagai berikut;

Dimana;

$$
\mathrm{KEP}=\mathrm{b} 0+\mathrm{b} 1 \mathrm{TGB}+\mathrm{b} 2 \mathrm{REL}+\mathrm{b} 3 \mathrm{RES}+\mathrm{b} 4 \mathrm{ASS}+\mathrm{b} 5 \mathrm{EMP} .
$$

$\mathrm{KEP}=$ Kepuasan pelanggan hasil estimasi

TGB $=$ Tangible

$\mathrm{REL}=$ Reliability

RES $=$ Responsiveness

ASS $=$ Assurance

$\mathrm{EMP}=$ Emphaty

Sedangkan :

b0 = Kepuasan pelanggan jika TGB, REL, RES, ASS, dan EMP bernilai nol b1, b2, b3, b4 dan b5 berturut-turut adalah koefisien regresi variabel tangible, reliability, responsiveness, assurance, dan emphaty.

Uji t Statistik dilakukan terhadap hipotesis yang telah ditetapkan dengan ketentuan sebagai berikut;

Hipotesis;

Ho: bi $=0$ artinya tidak ada pengaruh

$\mathrm{Ha}: \mathrm{bi}=0$ artinya ada pengaruh

Taraf signifikansi yang digunakan adalah $5 \%$ dengan degree of freedom $(\mathrm{df})=(\mathrm{k}),(\mathrm{n}-\mathrm{k}-\mathrm{l})$.

Rumus t hitung $=$ bi : Sbi

bi $=$ Koefisien regresi masing-masing variabel

Sbi $=$ Standard error koefisien regresi masing-masing variabel

Sedangkan kriteria pengujian:

- Apabila t hitung > t tabel, maka Ho ditolak

- Apabila t hitung < t tabel, maka Ho diterima.

Pengujian F statistik digunakan untuk melihat apakah independent variable secara bersama-sama mempengaruhi dependent variable (Ghozali, 2004). Perhitungan uji $\mathrm{F}$ ini dilakukan dengan program kompuer SPSS versi 10.0 terhadap Hipotesis yang diuji; dengan ketentuan :

Ho: jika $b 1=b 2=b 3=b 4=0$, artinya tidak ada pengaruh

Ha: jika $b 1=b 2=b 3=b 4=0$, artinya ada pengaruh. $(n-k-1)$.

Taraf signifikansi yang digunakan adalah 5\% dengan degree of freedom $(\mathrm{df})=(\mathrm{k})$, 
F hitung $=(\mathrm{R} 2 / \mathrm{k}):(1-\mathrm{R} 2) /(\mathrm{n}-\mathrm{k}-\mathrm{l})$

$\mathrm{R} 2$ = Koefisien determinasi

$\mathrm{k}=$ Derajat bebas pembilang

$(\mathrm{n}-\mathrm{k}-\mathrm{l})=$ Derajat bebas penyebut

Kriteria pengujian:

Apabila F hitung > F tabel, maka Ho ditolak

Apabila F hitung < F tabel, maka Ho diterima.

\section{BMT Tamzis}

Baitul maal wat tamwil yang lebih dikenal dengan BMT adalah sebuah lembaga keuangan mikro syariah yang biasanya berbadan hukum koperasi, yang lebih dikenal dengan Koperasi Jasa Keuangan Syariah (KJKS). Dalam operasionalnya telah dijabarkan dalam Keputusan Menteri Koperasi dan Usaha Kecil dan Menengah Republik Indonesia Nomor, 91/Kep/M.KUKM/IX/2004 tentang Petunjuk Pelaksanaan Kegiatan Usaha Koperasi Jasa Keuangan Syariah. Menurut Kepmen No. 91/Kep/M.KUKM/IX/2004, Koperasi Jasa Keuangan Syariah adalah koperasi yang kegiatan usahanya bergerak di bidang pembiayaan, investasi, dan simpanan sesuai pola bagi hasil (syariah). BMT adalah lembaga keuangan mikro syariah yang mempunyai ciri khas melakukan kegiatan profit oriented dengan Baituttamwil-nya, dan social oriented dengan Baitulmaal-nya.

Koperasi Jasa Keuangan Syariah (KJKS) Baituttamwil TAMZIS dibentuk pada tahun 1992 di Wonosobo Jawa Tengah. Tanggal 14 November 1994, KJKS TAMZIS mendapat status badan hukum dengan nomor 12277/B.H/VI/XI/1994 dari Departemen Koperasi. Kantor pusat KJKS BMT TAMZIS berada di Jl. S Parman 46 Wonosobo, dan memiliki Motto "Berkembang Penuh Barokah". Dengan NPWP 1.606.549.2-524. BMT TAMZIS kini memiliki lebih dari tiga puluh ribu anggota dan telah memiliki beberapa kantor cabang dan kantor pembantu di DIY, Jateng, Jabar dan DKI Jakarta.

Pada tahun 2003 dengan prestasi dan kinerja yang terus meningkat, BMT Tamzis mendapat izin dari Departemen Koperasi Republik Indonesia untuk membangun cabang di berbagai kota di Indonesia. Selain di Wonosobo Jawa Tengah, BMT Tamzis saat ini memiliki kantor cabang di beberapa area, antara lain: Yogyakarta, Jakarta, Bandung, Banyumas, Magelang, Klaten, Semarang dan akan terus mengembangkan diri ke kota-kota lain.

BMT Tamzis memiliki Visi untuk menjadi lembaga keuangan mikro syariah yang utama terbaik terpercaya. Misinya adalah : 1) Membantu dan memudahkan masyarakat mengembangkan kegiatan ekonomi produktifnya. 2) Mendidik masyarakat untuk jujur, bertanggungjawab, profesional dan bermartabat. 3) Menjaga kesucian umat dari praktek riba yang menindas dan dilarang agama. 4) Membangun dan mengembangkan sistem ekonomi yang adil, sehat dan sesuai syariah. 5) Menciptakan sistem kerja yang efisien dan inovatif.

Produk-produk BMT Tamzis adalah :

a. Simpanan MUTIARA dengan sifat :

\section{Mudah}

1) Setoran dan pengambilan dapat dilayani di semua kantor BMT Tamzis.

2) Setoran dan pengambilan dapat dilayani di tempat anggota.

\section{Multiguna:}

1) Sangat cocok bagi yang memiliki usaha perdagangan di pasar maupun sentra usaha lainnya. 
2) Dapat digunakan sebagai simpanan untuk pendidikan, Walimah, Qurban, Aqiqah dan Haji.

\section{Barokah:}

Menggunakan prinsip Wadiah wad Dhamanah, yaitu BMT Tamzis menerima titipan dari anggota kemudian disalurkan ke usaha yang produktif.

b. IJABAH (Investasi Berjangka Mudharabah) :

1) Dikelola berdasarkan prinsip yang adil.

2) Disalurkan untuk membiayai pedagang dan pengusaha kecil.

3) Disalurkan hanya untuk kegiatan usaha yang halal.

4) Perolehan bagi hasil yang menguntungkan dan kompetitif.

5) Mudah dalam bertransaksi, kami siap datang ketempat Anda.

6) Berpengalaman lebih dari 16 tahun.

7) Memiliki jaringan tingkat nasional.

c. Pembiayaan Mikro Syariah :

1) Pembiayaan diperuntukkan bagi pengusaha mikro sebagai tambahan modal usaha dan investasi.

2) Diutamakan untuk para pedagang di pasar.

3) Usaha yang dibiayai sudah berjalan minimal satu tahun.

4) Menggunakan prinsip mudharabah Muqayadah dan Murabahah.

5) Persyaratan mudah, tanpa biaya Administrasi dan Provisi.

\section{Program-program BMT TAMZIS diantaranya :}

a. Program Divisi Tamaddun :

1) Bina Siswa Cerdas (BSC).

Program ini disediakan untuk anak-anak miskin agar terjaga kelangsungan pendidikannya, dimaksudkan sebagai bantuan untuk keperluan pendidikannya.

2) Sanggar Remaja Inovatif

Upaya memberikan berbagai kegiatan untuk remaja berupa sanggar, membina kepribadian dan kedewasaan intelektual, emosional serta spiritualnya. Misalnya kelompok musik, kursus-kursus bahasa asing, ketrampilan komputer, kerajinan, automotif, pertukangan dan sebagainya.

3) Wanita Produktif

Bantuan program untuk para wanita, misalnya kegiatan ketrampilan membatik, tenun, terakota, anyaman serat, dan lainnya, dimaksudkan agar para wanita dapat menghasilkan produk yang bisa menambah penghasilan wanita miskin.

4) Desa Integral

Program ini dimaksudkan untuk membantu pembangunan pedesaan yang khususnya pengembangan sumber daya manusia, potensi pemanfaatan alam untuk dikembangkan menjadi potensi ekonomis dan berwiraswasta, mengajak masyarakat menjadi subjek atas dirinya sendiri melalui pendekatan partisipatif. Upaya patisipatif membangun masyarakat secara menyeluruh dan terintegrasi, meliputi aspek spiritual, intelektual, fisik dan ekonomi.

b. Divisi Pendukung Tamaddun

1) Majalah Tamaddun

Sebagai media publikasi dan edukasi ekonomi syariah yakni memberikan pemahaman tentang ekonomi syariah dan lembaga keuangan mikro syariah.

2) PUJASERA (Pusat Jajan Selama Ramadhan) 
PUJASERA merupakan kegiatan rutin yang dilakukan sejak tahun 2006 dan pesertanya selalu meningkat tiap tahunnya. Berlokasi di sepanjang Jl. Veteran Wonosobo, pada setiap bulan Ramadhan. Merupakan kegiatan pemberdayaan para pedagang mikro dan kecil yang menyediakan hidangan buka puasa. TAMZIS memfasilitasi peralatan berdagang secara gratis selama bulan ramadhan. Diramaikan dengan kegiatan berbagai lomba bagi anakanak, pengajian menjelang berbuka puasa.

3) Pelatihan

a) Pelatihan khutbah jum'at bagi para pengelola BMT Tamzis. Diantaranya berisi tema ekonomi syariah.

b) Pelatihan ekonomi syariah bagi guru-guru ekonomi pada SLTA se-Kabupaten Wonosobo, Kabupaten Banjarnegara, diberikan sebagai wujud peran sosial BMT Tamzis memberikan edukasi kepada masyarakat.

c) BMT Tamzis bekerjasama dengan Tim Penanggulangan Flu Burung Muhammadiyah Wilayah Yogyakarta mengadakan diseminasi kepada masyarakat agar dapat menjaga kebersihan sebagai upaya pencegahan meluasnya flu burung.

d) Berbagai Aksi tanggap bencana telah dilakukan oleh BMT Tamzis bekerjasama dengan beberapa lembaga sosial seperti Dompet Dhuafa', LAZISMU dan Asosiasi BMT di Jawa Tengah.

4) Divisi Penjamin Ta'awun

Divisi Penjaminan TAMZIS mengelola dana yang diperuntukkan khusus bagi penjaminan atas beberapa risiko yang mungkin timbul dari proses pembiayaan nasabah. Risiko terkena berbagai bencana daintaranya adalah kebakaran, gempa bumi, dan bencana lainnya yang dapat berakibat meninggal dunia atau sakit keras sehingga tidak dapat beraktifitas.

Pertanyaan-pertanyaan dalam kuesioner dalam penelitian ini merupakan jenis pertanyaan tertutup kepada nasabah untuk menganalisis kepuasannya. Melalui metode pengukuran berskala likert yang terdiri dari lima pilihan jawaban, yaitu sangat memuaskan (bernilai 5), memuaskan (bernilai 4), cukup memuaskan (bernilai 3), tidak memuaskan (bernilai 2), dan sangat tidak memuaskan (bernilai 1).

\section{Pembahasan}

Kuesioner telah didistribusikan kepada para nasabah di masing-masing kantor Cabang BMT Tamzis, masing-masing sejumlah 10 kuesioner pada 33 kantor Cabang, sehingga total 330 eksemplar. Kuesioner kembali didapatkan berjumlah 320 eksemplar.

Data yang diperoleh dengan cara penyebaran kuesioner tersebut terbukti valid dan reliabel, jika dilakukan uji validitas dengan menguji homogenitas item, dan reliabilitas terhadap butir-butir pertanyaan dalam kuesioner dengan menghitung Cronbrach alpha. Instrumen untuk mengukur masing-masing variable dikatakan reliabel jika memiliki Cronbrach alpha lebih besar dari 0.50 (Nunnaly, 1967).

Dari hasil uji reliabilitas dan validitas menunjukkan bahwa variabel-variabel tersebut telah reliabel dan telah valid. Hasil analisis data uji reliabilitas dan validitas diperoleh nilai koefisien determinasi $(\mathrm{R} 2)$ sebesar $=0,765$, artinya 76,5\% dari variasi kepuasan nasabah dipengaruhi oleh tangible, reliability, responsiveness, assurance, dan empathy. Sedangkan 23,5\% sisanya dipengaruhi oleh variabel lain yang tidak diteliti.

Hasil pengujian hipotesis tentang pengaruh kualitas jasa tangible, reliability, responsiveness, assurance, dan empathy terhadap kepuasan nasabah diperoleh Fhitung > Ftabel $(27,744>3,46)$ pada taraf signifikansi 5\% (Solimun, 2006). Hal ini dapat dimaknai bahwa kuesioner dapat dipergunakan untuk mengukur dan menganalisis pengaruh dan 
signifikansi jasa yang bersifat tangible, reliability, responsiveness, assurance, dan empathy terhadap kepuasan nasabah di masing-masing Kantor Cabang BMT Tamzis.

Hasil analisis regresi berganda terhadap data dari kuesioner nasabah yang telah diperoleh didapatkan sebagaimana pada tabel berikut :

Tabel 1 Hasil Analisis Regresi Berganda

\begin{tabular}{|c|c|c|c|}
\hline & Koefisien & $t_{\text {hitung }}$ & Signifikansi \\
\hline Konstanta & $-9,880$ & & \\
\hline Tangibles & 0,698 & 3,990 & 0,002 \\
\hline Reliability & 0,728 & 3,989 & 0,000 \\
\hline Responsiveness & 0,759 & 3,976 & 0,000 \\
\hline Assurance & 0,342 & 4,215 & 0,001 \\
\hline Empathy & 0,404 & 3,986 & 0,003 \\
\hline $\mathrm{R}$ & 0,376 & & \\
\hline $\mathrm{R}^{2}$ & 0.141 & & \\
\hline $\mathrm{F}_{\text {statistik }}$ & 27,744 & & \\
\hline
\end{tabular}

Sumber: Data primer diolah.

Hasil analisis data diperoleh nilai koefisien determinasi (R2) sebesar $=0,141$, artinya $14,1 \%$ dari variasi kepuasan nasabah dipengaruhi oleh tangible, reliability, responsiveness, assurance, dan empathy. Sedangkan 85,9\% sisanya dipengaruhi oleh variabel lain yang tidak diteliti, sehingga diperlukan pada kesempatan yang akan datang dilakukan penelitian.

Hasil pengujian hipotesis tentang pengaruh kualitas jasa tangible, reliability, responsiveness, assurance, dan empathy terhadap kepuasan nasabah diperoleh Fhitung > Ftabel $(27,744>3,46)$ pada taraf signifikansi 5\% (Solimun, 2006). Hal ini dapat dimaknai bahwa terdapat pengaruh yang signifikan jasa pada sisi tangible, reliability, responsiveness, assurance, dan empathy terhadap kepuasan nasabah di masing-masing Kantor Cabang BMT Tamzis.

Hipotesis yang telah diajukan dapat dinyatakan telah terbukti berpengaruh signifikan dan dapat diterima. Hasil uji t dapat diketahui bahwa variabel assurance merupakan variable yang memberikan pengaruh dominan terhadap kepuasan nasabah.

Hal ini dapat dilihat dari nilai thitung variabel assurance $(4,215)$ lebih tinggi dari thitung variabel lainnya, tangibles $(3,990)$, responsiveness $(3,989)$, reliability $(3,976)$, dan emphaty $(3,986)$. Hal ini berarti bahwa keterjaminan dalam memberikan pelayanan oleh BMT Tamzis menyebabkan nasabah merasa lebih puas dibanding bidang lainnya. Rata-rata kelima variable tersbut didapatkan sebesar 4,031, sehingga didapatkan bahwa rata-rata pelanggan merasakan kepuasan atas kelima faktor tersebut sebesar 4,031 dalam sekala 1 sampai dengan 5.

Adapun persamaan regresi yang diperoleh adalah sebagai berikut:

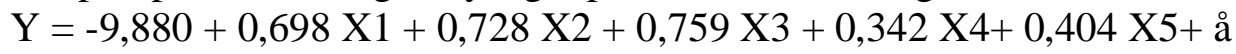

Persamaan ini menunjukkan bahwa tangible, reliability, responsiveness, assurance, dan empathy merupakan variable-variabel yang berpengaruh signifikan terhadap kepuasan nasabah. Dapat dimaknai bahwa jika terjadi peningkatan kualitas pelayanan jasa oleh para karyawan BMT Tamzis, maka dapat dipastikan nasabah akan merasa puas. Pemenuhan kebutuhan atau keinginan nasabah yang telah ada dapat terlayani oleh produk jasa BMT Tamzis sehingga program-program BMT Tamzis dapat ditawarkan pula kepada para calon 
nasabah lainnya atau nasabah yang telah ada ditawari dengan produk selain yang telah didapatkan.

Hasil analisis secara keseluruhan diperoleh bahwa tangible, reliability, responsiveness, assurance, dan empathy secara parsial maupun secara bersama-sama berpengaruh positif terhadap kepuasan nasabah. Puas atau tidaknya nasabah dipengaruhi oleh persepsi nasabah terhadap pelayanan BMT Tamzis, setidak-tidaknya sisi tangible, reliability, responsiveness, assurance, dan empathy yang diberikan oleh pihak BMT Tamzis di masing-masing Kantor Cabang.

Kualitas produk jasa merupakan keseluruhan ciri serta sifat yang berpengaruh pada kemampuannya memenuhi kebutuhan nasabah. Definisi ini berpusat pada nasabah, di mana nasabah mempunyai kebutuhan dan pengharapan tertentu. Sebelum mengambil keputusan, nasabah akan berusaha untuk mencari informasi yang berhubungan dengan jasa yang dibutuhkan. Pencarian informasi yang bersifat aktif dapat berupa kunjungan terhadap beberapa BMT untuk membuat perbandingan kualitas pelayanan. Sedangkan pencarian informasi pasif adalah hanya dengan membaca atau pengiklanan di majalah atau surat kabar. Informasi yang didapat calon nasabah digunakan untuk memperoleh gambaran yang lebih jelas mengenai alternatif-alternatif yang dihadapi serta daya tarik masing-masing alternatif (Tjiptono, 2012).

Setelah mengambil keputusan, nasabah akan mengalami beberapa tingkatan kepuasan atau ketidakpuasan. Kepuasan dan ketidakpuasan terhadap suatu produk akan mempengaruhi perilaku nasabah, yakni dalam hal kemungkinan kembali datang ke BMT Tamzis atau meninggalkannya.

Hasil penelitian ini menunjukkan bahwa untuk mendapatkan loyalitas dari pelanggan, perusahaan harus memperhatikan beberapa faktor yang dapat mempengaruhi kepuasan nasabah. Faktor pertama dan utama yang dapat mempengaruhi kepuasan pelanggan adalah kualitas pelayanan. Sebagai perusahaan yang bergerak dalam bidang pelayanan jasa, kualitas pelayanan haruslah diutamakan.

Kualitas pelayanan dapat diartikan sebagai tingkat keunggulan yang diharapkan dan pengendalian atas tingkat keunggulan tersebut untuk memenuhi keinginan pelanggan dan kualitas pelayanan yang optimal. Pihak BMT Tamzis harus memberikan pelayanan yang prima dan unggul. Pemberian bukti pelayanan secara langsung, kehandalan petugas dalam memberikan pelayanan, ketepatan daya tangkap petugas dalam menanggapi keluhan pelanggan, pemberian jaminan pelayanan, dan pemberian perhatian terhadap keluhan pelanggan, membuat pelanggan merasa diperhatikan dan pada akhirnya akan setia kepada BMT Tamzis. Peningkatan kualitas jasa melalui pelaksanaan tangible, reliability, responsiveness, assurance, dan empathy atas berbagai bidang layanan dimaksudkan untuk mencapai tingkatan kepuasan nasabah yang tinggi.

Kualitas pelayanan adalah kunci yang sangat penting untuk meraih pasar. Penelitian terhadap kepuasan konsumen merupakan reaksi konsumen terhadap pelayanan yang diberikan BMT Tamzis. Tingkat kepuasan yang tinggi dan optimal atas pelayanan sangat relevan dan harus dapat dicapai oleh perusahaan yang berorientasi pada konsumen. Menurut Kotler (2010: 56), salah satu tindakan untuk memuaskan konsumen adalah dengan cara memberikan pelayanan kepada konsumen dengan sebaik-baiknya. Kepuasan pelanggan yaitu nilai total pelanggan yang terdiri dari nilai produk, nilai pelayanan, nilai personal, nilai image (citra), dan biaya total yang terdiri dari biaya moneter, biaya waktu, biaya tenaga dan biaya pikiran. Pemasaran yang bergerak di bidang jasa sangat bertumpu pada sisi pelayanan, terutama peran dari para karyawan perusahaan. Pelayanan yang buruk yang dilakukan oleh karyawan akan langsung merusak bisnis jasa, karena menyebabkan 
konsumen enggan berhubungan kembali di masa mendatang, bahkan tidak menutup kemungkinan konsumen akan pindah ke BMT lain dengan harapan mendapatkan pelayanan yang lebih baik. Oleh sebab itu, usaha untuk menjaga kepuasan konsumen sangat perlu dilakukan oleh BMT Tamzis.

\section{Kesimpulan} kesimpulan.

Berdasarkan hasil analisis yang telah diuraikan, maka dapat diambil beberapa

Pertama, pelayanan jasa pada pelanggan dengan mengukur tingkat kualitas pada dimensi tangible, reliability, responsiveness, assurance, dan empathy terhadap kepuasan nasabah didapatkan sebesar 4,031 pada skala 1 sampai dengan 5. Hal ini mengindikasikan bahwa BMT Tamziz harus mengupayakan pada setiap kesempatan harus dapat meningkatkan pelayanan kepada nasabah agar secara konsisten dilakukan optimalisasi pencapaian kepuasan nasabah, melalui upaya perbaikan pelayanan terus menerus dengan memberikan perhatian khusus pada standar kinerja pelayanan baik internal maupun eksternal.

Kedua, Telah tercapai pengaruh yang signifikan kualitas jasa pelayanan Kantor Cabang BMT Tamzis di DIY dan Jateng atas pelayanannya dari sisi tangible, reliability, responsiveness, assurance, dan empathy terhadap kepuasan nasabah, baik secara bersamasama maupun secara parsial.

Ketiga, Variabel assurance merupakan variabel yang dirasakan oleh nasabah telah memberikan pengaruh dominan terhadap kepuasan pelanggan. Hal ini berarti bahwa keterjaminan dalam memberikan pelayanan menyebabkan nasabah merasa puas, terlebih jika dapat diupayakan peningkatan sisi selain assurance, maka akan terbangun pelayanan sempurna kepada nasabah.

\section{Saran}

Berdasarkan hasil penelitian yang telah dipaparkan, yaitu analisis dimensi kualitas pelayanan yang terdiri dari lima dimensi yaitu: Assurance, Reliability, Tangibles, Empathy, dan Responsiveness terhadap kepuasan nasabah BMT Tamzis DIY dan Jawa Tengah, maka dapat disarankan sebagai berikut :

Pertama, Disarankan untuk ditingkatkan pelayanan kesemua bidang atau dimensinya sehingga tingkat kepuasan nasabah tercapai optimal dan sempurna.

Kedua, perlu dilakukan pengukuran kelima indikator atau bidang tersebut setiap waktu tertentu untuk segera dapat mengetahui saat mana diperlukannya upaya peningkatan jasa pelayanan pada sisi mana saja dengan segera.

Ketiga, indikator-indikator yang perlu menjadi prioritas untuk dikembangkan dan diperbaiki kualitasnya untuk meningkatkan kepuasan nasabah sebagaimana tertulis pada kolom saran oleh nasabah adalah: "Tidak menggunakan sistim bunga atau bagi hasil atau yang semacamnya, baik pada pada tabungan maupun kredit yang lebih memberatkan dibanding bank konvensional sehingga hati nasabah menjadi tenteram", dan "Ketersediaan anjungan tunai mandiri (ATM)", serta "Peralatan menghitung lembaran uang yang digunakan bank modern sehingga pelayanan cepat dan tepat ". Juga harapan nasabah agar BMT Tamzis memberikan "hadiah kesetiaan tahunan", sebagai taliasih kepada nasabah yang telah berbilang tahun menjadi nasabah.

Keempat, disarankan kepada peneliti berikutnya agar meneliti variabel-variabel lainnya untuk mengukur dan menganalisis kepuasan pelanggan pada BMT Tamzis. 


\section{Daftar Pustaka}

Andespa, Roni. (2016). Strategi Pelayanan Bank Konvensional dan Syariah: Prioritas Pelayanan Fisik dan Empati. Al-Masraf: Jurnal Lembaga Keuangan dan Perbankan, 1 (2): 143-159.

Arikunto, Suharsimi, 2009. Manajemen Penelitian. Cetakan kesepuluh. Jakarta: PT Rineka Cipta.

Azwar, Saifuddin. 1998. Metode Penelitian. Edisi ke 1. Putaka Pelajar. Yogyakarta.

Cronin,J.J.Jr., and Taylor, A.S. 1992. Measuring Service Quality: A Reexamination and Extension. Journal of Marketing, Vol.56, July, pp.55-68.

Febriana, Nina Indah, 2016. Analisis Kualitas Pelayanan Bank Terhadap Kepuasan Nasabah Pada Bank Muamalat Indonesia Kantor Cabang Pembantu Tulungagung. Jurnal An-Nisbah, Vol. 03, No. 01, Oktober 2016 : 146.

Ghozali, Imam, 2002. Aplikasi Analisis Multivariate dengan Program SPSS. Semarang: Badan Penerbit Universitas Diponegoro.

2004. Model Persamaan Struktural, Konsep dan Aplikasi dengan Program Amos Vesi 5.0. Semarang: Universitas Diponegoro.

Ikhwal, Nuzul, 2017. Analisis Faktor-faktor Yang Mempengaruhi Kepuasan Nasabah Terhadap Pelayanan Bank Syariah Kota Batam. JEBI (Jurnal Ekonomi dan Bisnis Islam)-Volume 2, Nomor 2, Juli-Desember 2017 : 186.

Kotler, Phillip. 1997. Manajemen Pemasaran: Analisis, Perencanaan, Implementasi dan Kontrol. Edisi 9. Penterjemah Hendra Teguh. Penerbit PT. Prenhallindo. Jakarta.

Kotler, Philip. 2010. Manajemen Pemasaran. Jakarta: PT. Prenhalindo.

Martilla, J.A. and James, J.C. (1977) Importance-Performance Analysis. Journal of Marketing, 41, 77-79.

Muhammad. (2005). Manajemen Bank Syariah. Yogyakarta: AMPYKPN.

Nunnaly, J. 1967. Psychometric Methods. New York: McGraw Hill.

Parasuraman, A., Berry, Leonard L, and Zeithaml, Valarie A. 1985. "A Conceptual Model of Service Quality and Its Implications for Future Research". Journal of Marketing, Vol;. 49 (Fall), pp. 41-50.

Parasuraman, A., Berry, Leonard L, and Zeithaml, Valarie A. 1988, "SERVQUAL: AMultiple-Item Scale for Measuring Consumer Perceptions of Service Quality”. Journal of Retailing, Vol;. 64 (Spring), pp. 12-40.

Parasuraman, A., Berry, Leonard L, and Zeithaml, Valarie A. 1991. "Refinement and Reassessment of The SERVQUAL Scale". Journal of Retailing, Vol;. 67 No. 4 (Winter), pp. 420-450. 1994. "Reassessment of Expectations as a Comparison Standar in Measurung Service Quality: Implications for Future Research. Journal of Marketing, Vol;. 58 (January), pp. 111-124.

Rokhman, Wahibur, 2016. Pengaruh Biaya, Angsuran Dan Kualitas Pelayanan Terhadap Kepuasan Nasabah Pembiayaan BMT Di Kabupaten Kudus. Jurnal IQtishadia, Vol. 9, No. 2, 2016, 326-351. P-ISSN: 1979-0724, E-ISSN: 2502-3993.

Solimun, 2006. Metode Statistika. Malang: FMIPA Universitas Brawijaya.

Stanton, William J.; Michael J. Etsel and Bruce J. Walker. 1991. Fundamental of Marketing 9th ed. McGraw-Hill, Inc. New York.

Supranto, J. 2002. Metode Riset: Aplikasinya Dalam Pemasaran. Edisi Revisi. Penerbit PT. Rineka Cipta. Jakarta. 
Taylor, S. A., and Baker, T. L. (1994). An Assessment of the Relationship between Service Quality and Customer Satisfaction in the Formation of Consumers' Purchase Intentions. Journal of Retailing, 70(2), 163-178.

Tjiptono, Fandy. 1997. Manajemen Jasa. Penerbit Andi Offset. Yogyakarta.

Tjiptono, Fandy. 2012. Manajemen Jasa, dan Service Management. Yogyakarta: Andi. Tjiptono, F. \& G. Candra, (2012). Service, Quality dan Satisfaction. Yogyakarta: Andi.

Zeithaml, Valerie A. and Mary Jo Bitner, 1996. Services Marketing. New York: The McGraw-Hill Companies. Inc. 